\title{
Management of an Inappropriately Treated Case of Auricular Hematoma
}

\author{
Yoonjoong $\mathrm{Kim}^{1}$, Jin Woong Choi ${ }^{1,2}$, and Yong-Ho Park ${ }^{1,2}$ \\ ${ }^{1}$ Department of Otolaryngology-Head and Neck Surgery, Chungnam National University Hospital, Daejeon, Korea \\ ${ }^{2}$ Department of Otolaryngology-Head and Neck Surgery, College of Medicine, Chungnam National University, Daejeon, Korea
}

$\begin{array}{ll}\text { Received } & \text { April 7, 2020 } \\ \text { Revised } & \text { May 25, 2020 } \\ \text { Accepted } & \text { June 21, 2020 }\end{array}$

Address for correspondence

Yong-Ho Park, MD, PhD

Department of Otolaryngology-Head

and Neck Surgery,

College of Medicine,

Chungnam National University,

Chungnam National University

Hospital, 282 Munhwa-ro, Jung-gu,

Daejeon 35015, Korea

Tel +82-42-280-7697

Fax +82-42-253-4059

E-mail parkyh@cnu.ac.kr
Othematoma is a condition in which blood collects beneath the perichondral layer of the pinna. Recurrent auricular hematoma can be a challenging medical problem, with complications resulting in ear deformity, therefore, appropriate management is important. Improper treatment can result in a deformity known as 'cauliflower ear' or 'wrestler's ear.' We report a case of othematoma that was inappropriately treated and present a review of current treatment options.

J Audiol Otol 2021;25(2):115-118

KEY WORDS: Hematoma · Ear auricle · Foreign bodies · Granulation tissue · Hemostatics.

\section{Introduction}

Hematoma of the ear typically occurs in sports-related injuries, particularly among wrestlers and boxers. Simultaneous application of blunt and shearing forces to the pinna can result in disruption of the perichondrium's attachment to the underlying cartilage with subsequent accumulation of blood in the subperichondrial space of the pinna. Appropriate management of auricular hematoma should aim toward achieving effective evacuation of the hematoma, prevention of recurrence, and a good cosmetic outcome. If not treated properly, it can cause a deformity known as 'cauliflower ear' or 'wrestler's ear.' There is no consensus on the best treatment method, and various surgical techniques have been described [1-8]. We report a case of othematoma that was inappropriately treated.

This is an Open Access article distributed under the terms of the Creative Commons Attribution Non-Commercial License (https://creativecommons.org/licenses/by-nc/4.0/) which permits unrestricted non-commercial use, distribution, and reproduction in any medium, provided the original work is properly cited.

\section{Case Report}

A 13-year-old female patient presented with a one-month history of painful swelling on her left ear. Her ear injury occurred when she was dashed against a wall. She was being treated by a general physician for three weeks prior to her admission, but the symptoms did not improve. She had a medical history of hydrocephalus, epilepsy, and mental retardation. No history of any coagulopathy was evident. Typical auricular landmarks were lost because of marked swelling with erythema. A 2-cm long previous incision scar was observed over the antihelix (Fig. 1). Needle aspiration failed to yield any diagnostic material.

Surgery was opted as the treatment plan. An incision was made over the antihelix along the previous incision site and the subcutaneous flap was elevated off the lesion (Fig. 2). While the skin flap was being elevated, numerous fragments of spongy material of various sizes were observed between the subcutaneous tissue and cartilage (Fig. 3). The hematoma, granulation tissue, fibrous tissue, fibronecrotic cartilage, and foreign material were removed by curettage and debridement. No packing materials or hemostatic agents were ap- 


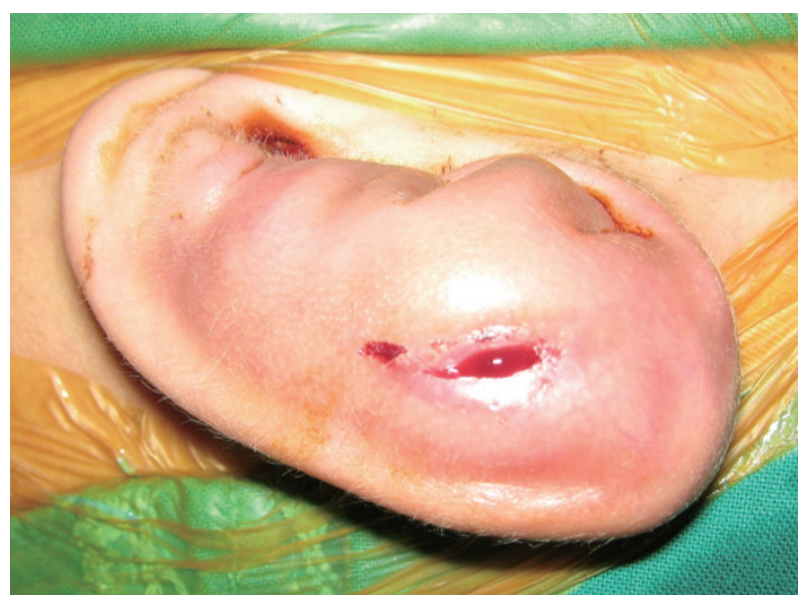

Fig. 1. Preoperative photograph. Auricular landmarks were lost, and a previous incision scar was observed over the antihelix.

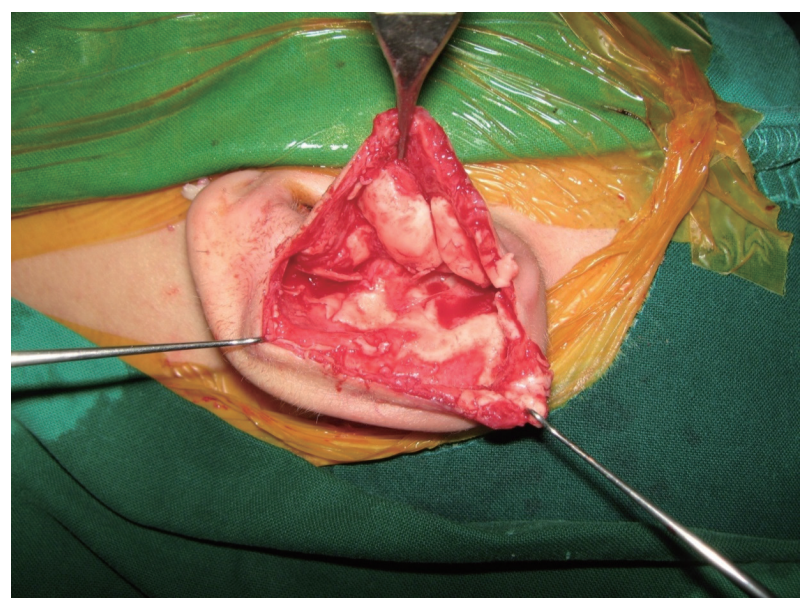

Fig. 2. Operative findings: an incision positioned on the antihelix along the previous incision site.

plied in the evacuated wound pocket. Skin was sutured with 3-0 nylon. Two Penrose drains were placed in the subperichondrial layer and bolsters were placed on the anterior and posterior aspect of the auricle, fixed with through-and throughsutures (Fig. 4).

Histopathologic examination of the debrided material showed mesh-like membranous foreign bodies with proliferative granulation tissue surrounded by inflammatory cells (Fig. 5). At two weeks follow-up, her affected ear had healed with desirable cosmetic result and no evidence of hematoma recurrence was observed (Fig. 6).

\section{Discussion}

A conventional surgical intervention for othematoma begins with a local field block using $2 \%$ lidocaine with epinephrine 1:100,000. Drainage is performed via a surgical incision on the helical rim or margin of the most prominent area

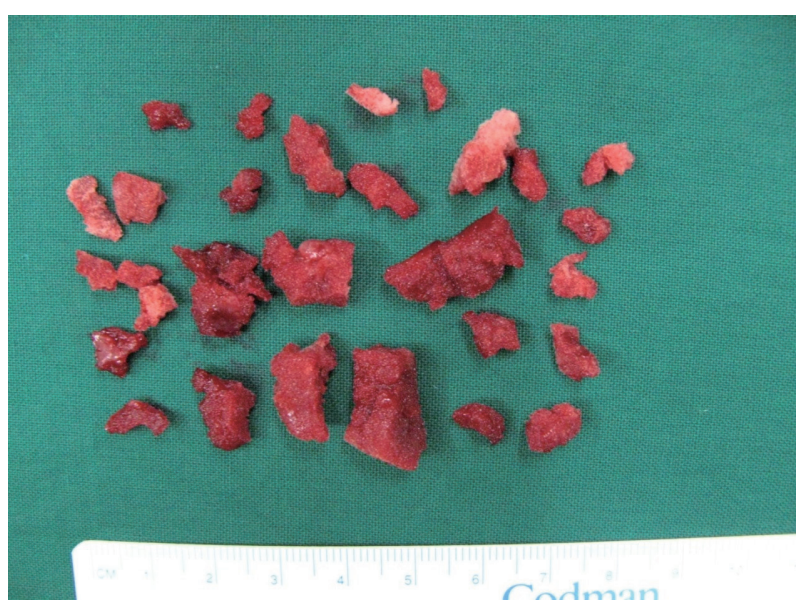

Fig. 3. Removed fragments of material of various sizes.

followed by removal or irrigation of the extravasated blood and fluids. To prevent recurrence, a drain, sutures, or adequate compression using a splint or bolster should be applied for several days to inhibit dead space formation [2-9]. Recently, steroid or OK-432 application has also been considered as an option [1,10-12] and a previous report demonstrated good results with fibrin glue hemostatic material [13].

There are several synthetic biomaterials that can be used for bleeding control during surgical procedures. These may be used for hemostasis, as skin adhesive, or packing material. In order to use these materials appropriately, it is important to know the physical characteristics or details of these materials (Table 1). They can be classified as absorbable or non-absorbable materials and accordingly, may be used either internally or externally. For example, a representative hemostatic material called fibrin sealant (TISSEEL, Baxter International Inc., Deerfield, IL, USA) is a liquid compound that can be used as a supportive material for bleeding control after applying a surgical suture or ligation. Even though this fibrin sealant completely resorbs in 10 to 14 days, it should not be used in a way that it is directly in contact with the circulatory system or highly vascularized tissue, as it may result in a thromboembolic event. Furthermore, the company has recommended minimal use of this material. Another material called hydroxylated polyvinyl acetate $\left(\right.$ Merocel $^{\mathbb{Q}}$, Medtronic ENT, Jacksonville, FL, USA) is an artificial sponge tampon with micro-oxidized cellulose. It is widely used for bleeding control in epistaxis, septal surgery, and sinus surgery. It can offer structural support for the prevention of postoperative stenosis in rhinoplasty. It has also been used as an ear wick in external auditory canal trauma. This material is soft and has a high capacity to absorb water with good elasticity but clinicians should be aware that it is non-absorbable and does not exhibit any antimicrobial properties. Extra caution should be taken before its use in cases 
Fig. 4. Immediate postoperative photograph. Two Penrose drains were inserted, and bolsters were placed on the anterior and posterior aspects of the auricle.
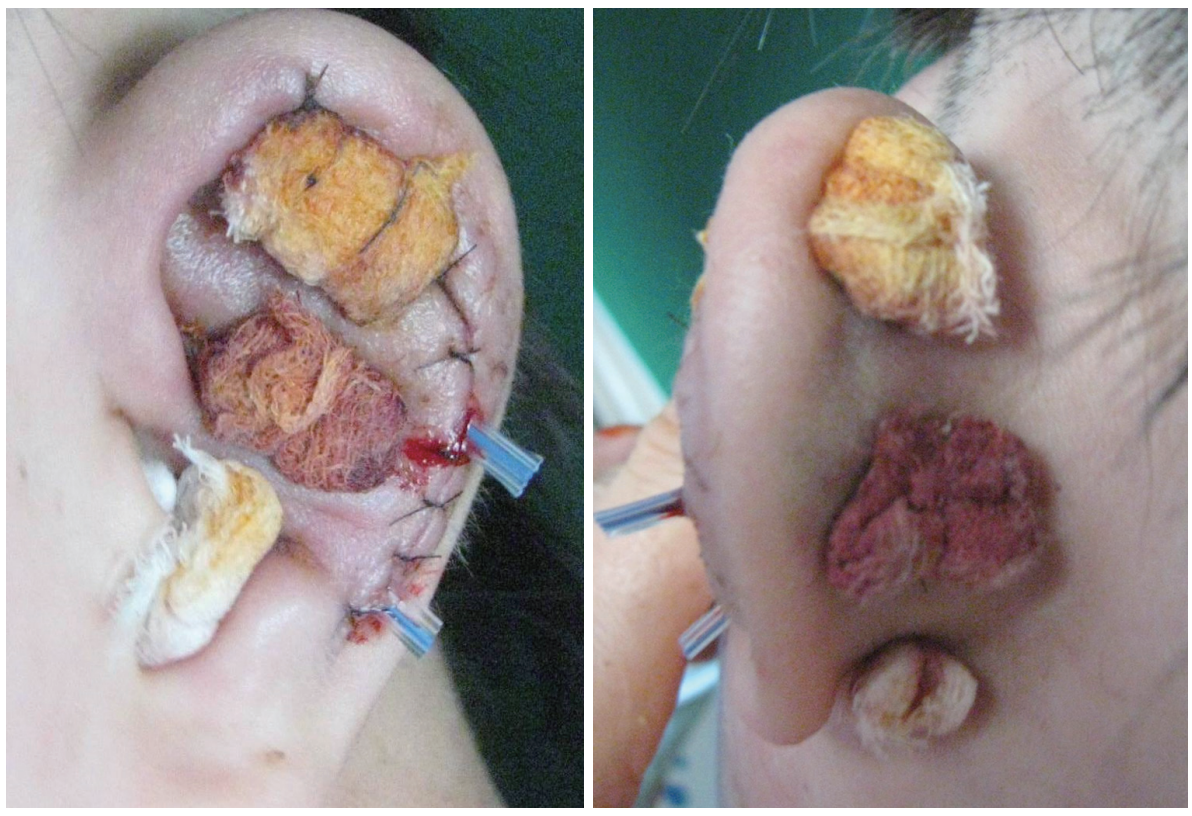

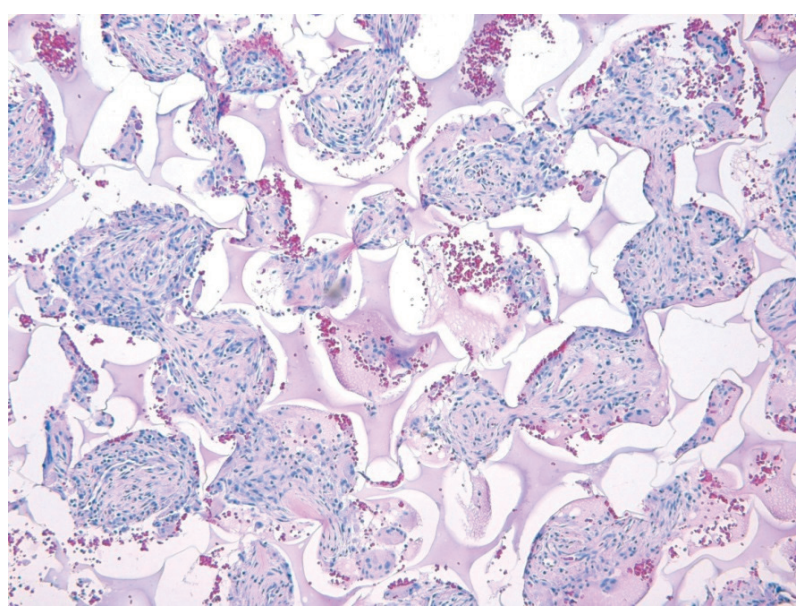

Fig. 5. Pathologic findings: mesh-like membranous foreign body with inflammatory cells and granulation (hematoxylin and eosin, $\times 100)$.

with pre-existing infection because of the possibility of toxic shock syndrome. This kind of hemostatic packing material should not be used internally because it may not be easily removed. It is important that clinicians are aware of the advantages and disadvantages of the various medical biomaterials before their use.

In this case, a less well-informed general physician inappropriately treated an auricular hematoma by leaving a nonabsorbable hemostatic material in a closed cavity that eventually lead to chondritis and cartilage necrosis. It is crucial that doctors have a proper understanding of the hemostatic materials before use.

In conclusion, appropriate management of auricular hematoma should be aimed at achieving effective evacuation of the

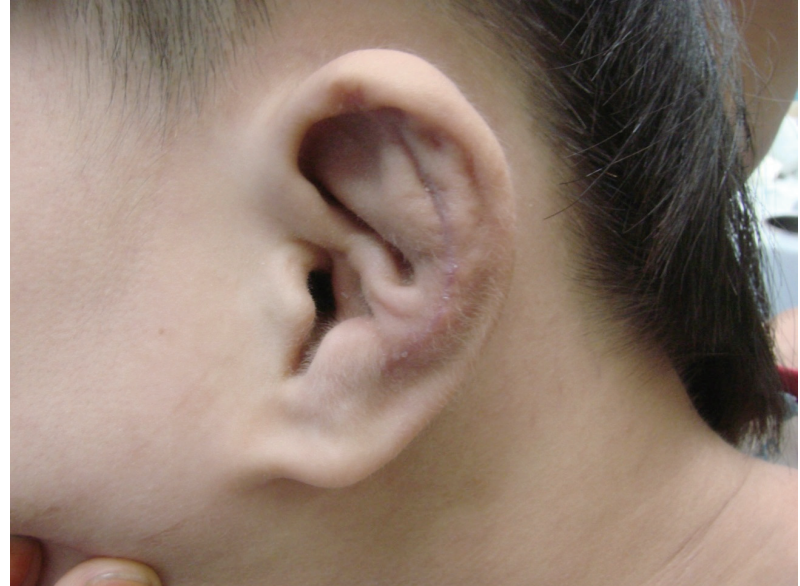

Fig. 6. Postoperative photographs at three weeks follow-up showing relatively good cosmetic result (lateral view).

hematoma, preventing recurrence, and providing a good cosmetic outcome. Doctors should be aware of the characteristics and details of the various hemostatic materials before use, to prevent adverse irreversible sequelae or complications.

\section{Acknowledgments}

This work was supported by the Basic Science Research Program through the National Research Foundation of Korea (NRF) (NRF-2018R1A2B2005022 and 2019M3E5D1A02068573).

\section{Conflicts of interest}

The authors have no financial conflicts of interest.

\section{Author Contributions}

Conceptualization: Yong-Ho Park. Funding acquisition: Yong-Ho Park. Investigation: Yoonjoong Kim and Yong-Ho Park. Project ad- 
Table 1. Various hemostatic materials

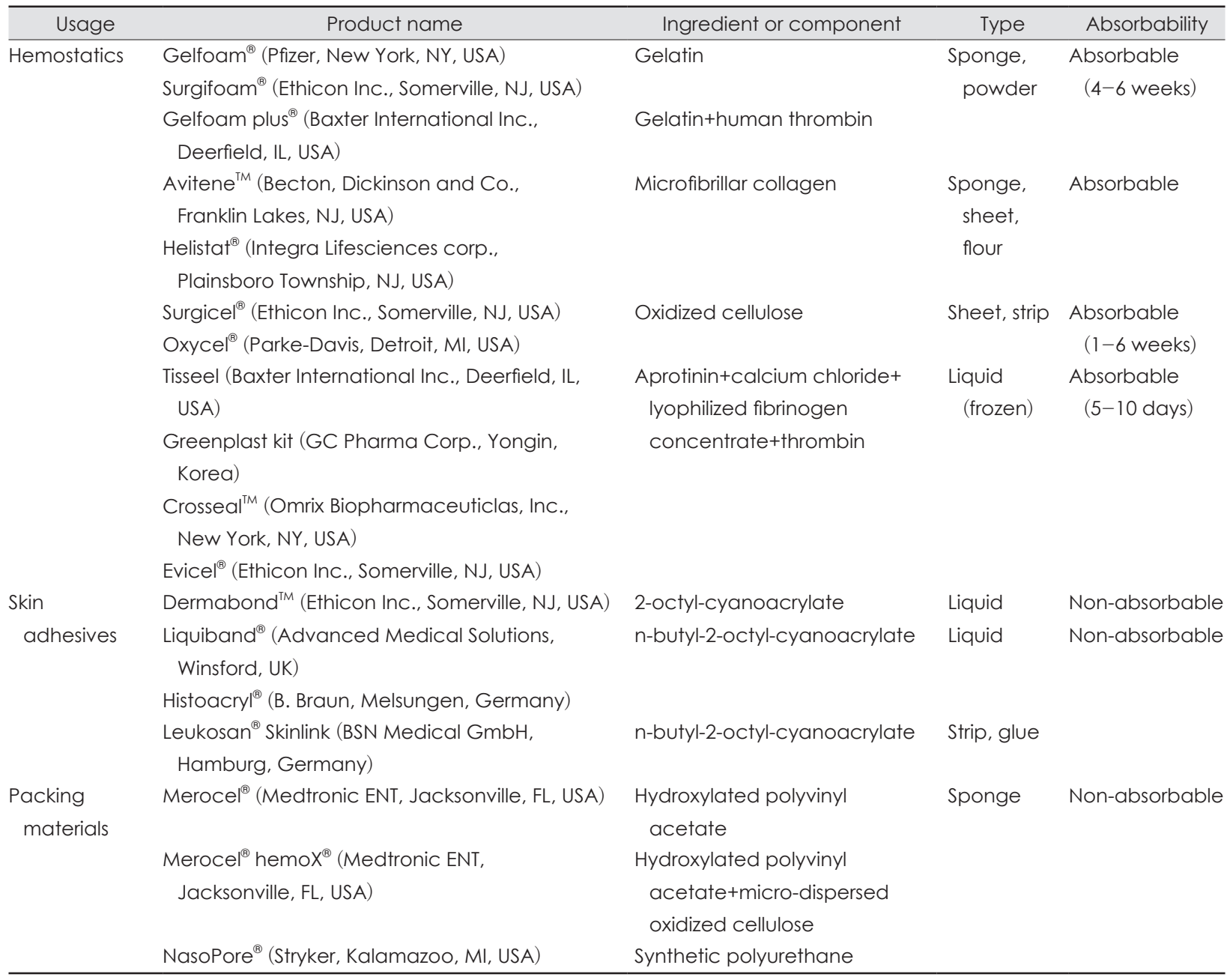

ministration: Yong-Ho Park. Supervision: Jin Woong Choi and YongHo Park. Visualization: Yoonjoong Kim and Yong-Ho Park. Writingoriginal draft: Yoonjoong Kim and Yong-Ho Park. Writing—review \& editing: Yoonjoong Kim. Approval of final manuscript: all authors.

\section{ORCID iDs}

Yoonjoong Kim https://orcid.org/0000-0002-9589-9244 Jin Woong Choi https://orcid.org/0000-0003-3101-6841

Yong-Ho Park https://orcid.org/0000-0003-2106-3791

\section{REFERENCES}

1) Greywoode JD, Pribitkin EA, Krein H. Management of auricular hematoma and the cauliflower ear. Facial Plast Surg 2010;26:451-5.

2) Summers A. Managing auricular haematoma to prevent "cauliflower ear.' Emerg Nurse 2012;20:28-30.

3) Okolugbo N. Treatment outcomes of auricular hematoma using corrugated rubber drains: a pilot study. Ann Med Health Sci Res 2013;3: 447-9.

4) Rah YC, Park MH. Use of silastic sheets with mattress-fashion sutures for the treatment of auricular hematoma. Laryngoscope 2015; 125:730-2.

5) Shakeel M, Vallamkondu V, Mountain R, Hussain A. Open surgi- cal management of auricular haematoma: incision, evacuation and mattress sutures. J Laryngol Otol 2015;129:496-501.

6) Garcia-Rodriguez L, Jones L. Ear bolster button. Laryngoscope 2018; 128:719-21.

7) Mohseni M, Szymanski T. Acute non-traumatic spontaneous auricular hematoma. Am J Case Rep 2019;20:204-6.

8) Dalal PJ, Purkey MR, Price CPE, Sidle DM. Risk factors for auricular hematoma and recurrence after drainage. Laryngoscope 2020;130: 628-31.

9) Kakarala K, Kieff DA. Bolsterless management for recurrent auricular hematomata. Laryngoscope 2012;122:1235-7.

10) Kubota T, Ohta N, Fukase S, Kon Y, Aoyagi M. Treatment of auricular hematoma by OK-432. Otolaryngol Head Neck Surg 2010;142: 863-6.

11) Brickman K, Adams DZ, Akpunonu P, Adams SS, Zohn SF, Guinness M. Acute management of auricular hematoma: a novel approach and retrospective review. Clin J Sport Med 2013;23:321-3.

12) Lee SY, Han SA, Park MH, Kim YH. Clinical implications of intralesional steroid injections in the management of otohematoma. Laryngoscope 2019;129:459-65.

13) Mohamad SH, Barnes M, Jones S, Mahendran S. A new technique using fibrin glue in the management of auricular hematoma. Clin J Sport Med 2014;24:e65-7. 